\title{
Pattern discrimination of Gaussian distributions of orientation and line length parameters
}

\author{
TERRENCE M. CAELLI* and DAVID C. FINLAY \\ The University of Newcastle, Newcastle, New South Wales, Australia
}

\begin{abstract}
The two pattern parameters, line length (L) and orientation ( $\theta$ ), have been salient in microelectrode studies and adaptation experiments with the vertebrate visual system, but have not been systematically examined in a pattern discrimination paradigm. It was argued that, because of their physiological importance, the detection of pattern differences should be predictable with known distributions of $L$ and $\theta$, using naive $S s$. It was also argued that the discriminability of the concatenation of $L$ and $\theta(L \theta)$ could be predicted from the individual $L$ and $\theta$ performance results. Results indicated support for both hypotheses and also implied the $\mathrm{L}$, discriminations were more difficult than $\theta$, using signal detection theory.
\end{abstract}

Quantitative approaches to the modeling and prediction of visual pattern discrimination are centered around two basic problems. The initial difticulty is that of procuring a basic representation for a pattern which embraces the known physiology of the vertebrate visual system. The second problem is that of characterizing such basic representsions in terms of a metric, $\mathbf{n}$-dimensional vector, or similar measures. For example, Zusne (1965) characterizes a pattern by means of moments about the $X$ and $Y$ axes. Such techniques have proven effective in predicting discrimination performance. However, it is of primary importance that the representation problem be investigated independently of this characterization problem, since inappropriate characterizations can distort the predictive value of a given representation (Caelli \& Keats, 1973).

In order to isolate both these problems, and deal with complex shapes, known distributions of parameters have to be employed such that a unique characterization can be obtained for the pattern representation. Consequently, the use of random polygons, etc., is not appropriate.

This experiment was concerned with investigating the representation of linear patterns in terms of line length and orientation parameters for the following reasons.

Considering the results of Hubel and Wiesel's $(1962,1968)$ research on vertebrates' visual cortex, recent researchers have been investigating the detectability of simple line segments in various orientations. Gilinsky and Cohen (1972) and Woll, Eriksen, and Hake (1970) have both demonstrated how the comparative orientations of mask and test

\footnotetext{
* This experiment was part of a $\mathrm{PhD}$ research program of the first-named author. Requests for reprints should be sent to T. $M$. Caelli. Department of Psychology. The University of Melbourne, Parkville, Vic.. 3052, Australia.
}

stimulus elements affect the detectability of the test stimulus, using striated line patterns. Similarly, Campbell and Kulikowski (1966), also using a masking paradigm, found that by increasing the angle between the mask and test gratings, the masking effect fell exponentially. These findings, together with those of Leibowitz and Harvey (1973), indicate that for shapes consisting of line segments orientation $(\theta)$ is a relevant representation parameter.

Although line-length distributions are a corequisite for studying the effect of orientation sensitivities. they have not been examined as the orientation parameter has been. However, it has been noted as an important pattern parameter, both in striated line segments (Breitmeyer, 1973) and random polygons (Zusne, 1970, p. 208). Since any linear shape (spatial union of line segments) is, to a great extent, determined by line length $(L)$ and orientation $(\Theta)$ parameters, it would seem important to establish their relative detectabilities in isolation, and in combination $(L \Theta)$, in order to construct a pattern representation consistent with the types of parameters the visual system detects.

A more elementary type of complex pattern which may vary only in orientations $(\Theta)$ and line lengths $(L)$ is the class of radial star patterns (Fig. 1). Figure 1a demonstrates how $\Theta$ may vary alone, and Fig. 16 how $\mathrm{L}$ may vary alone. Figure $1 \mathrm{c}$ illustrates variations in both $L$ and $\Theta(L \Theta)$.

By using Gaussian distributions of $L$ and $\Theta$, the basic pattern functions (frequency functions of $L$ and $\Theta)$ can be uniquely characterized by means of $\left(\mu_{\mathrm{X}}, \sigma_{\mathrm{X}}\right)$ (Hogg \& Craig, 1965, p. 96). This property of Gaussian functions avoids the characterization problem mentioned above.

Since $L$ and $\Theta$ are independently varied in radial star patterns, they may be clasified as independent random variables, and it can be shown that:

$$
\sigma^{2} L \theta=\sigma_{L}^{2}+o^{2} \Theta .
$$


(a)

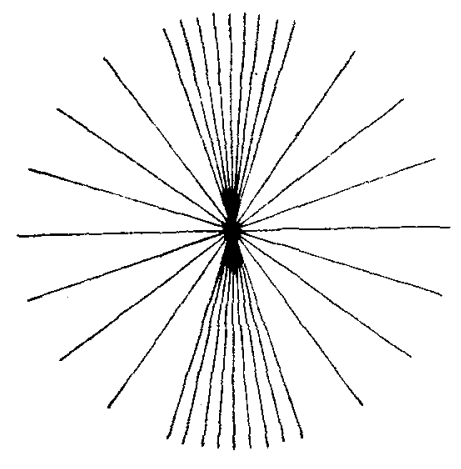

(c) (b)

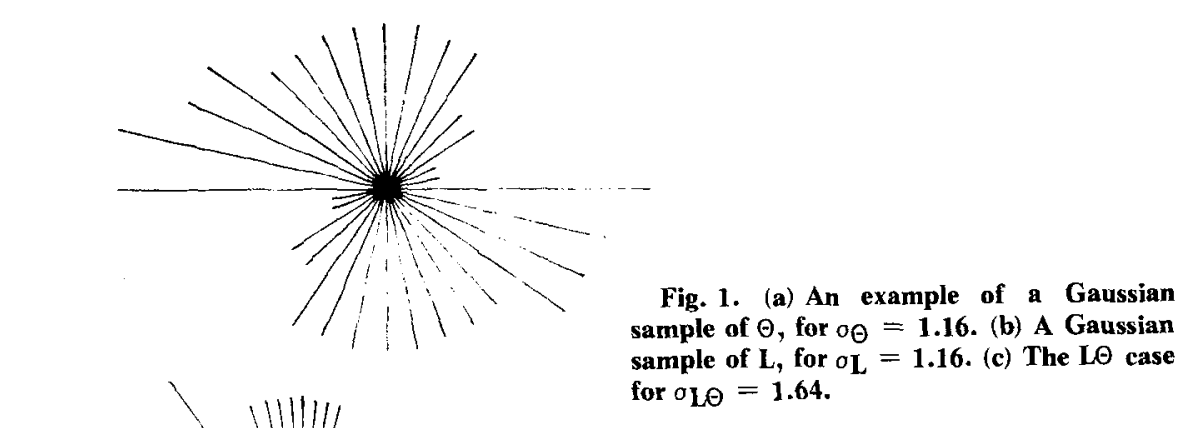

If the patterns are equated on means $\left(\mu_{\mathrm{X}}\right)$, then $\left[\sigma_{\mathrm{L}}, \sigma_{\Theta}, \sigma_{\mathrm{L} \Theta} \mid \sigma_{\mathrm{L} \Theta}=\left(\sigma^{2} \mathrm{~L}+\sigma^{2} \Theta\right)^{1 / 2}\right]$ uniquely characterizes the three classes of patterns illustrated in Fig. 1.

Weintraub and Hake (1962) have developed a model for the application of signal detection theory (SDT) to the visual discrimination of geometric squares and rectangles. They have experimentally demonstrated, by the use of the Gaussian assumption (Green \& Swets, 1966, p. 58), that the model has favorable application to visual perception. Following Weintraub and Hake, SDT may also be applied to visual pattern discrimination where the sensitivity function (d') can be directly related to pattern characterizations.

With Gaussian patterns equated on means, d' would measure the scale of discrimination between patterns differing in $\sigma_{X}$, while $\beta$ would represent the response criterion adopted by each $S$ for such discriminations.

In this experiment, the detection paradigm was constructed as follows. A "noise" stimulus consisted of two identical patterns of given $\sigma_{\mathrm{X}}\left(\sigma_{\mathrm{XN}}\right)$, while a "signal" stimulus consisted of two different patterns, one identical to those used in the noise stimulus, the other having a different $o_{X}\left(\sigma_{X S}\right)$.

Consequently, for different values of $\sigma_{X S}$ and $\sigma_{X N}$, false-alarm and hit probabilities could be calculated over Ss from "different" responses on the noise and signal stimuli, respectively. Similarly, for each pattern type ( $L, \theta$, or $L \Theta)$, a hit and false-alarm rate could be calculated for each $S$ over the various signal and noise stimuli presentations. From these hit and false-alarm responses, $d^{\prime}$ and $\beta$ could be calculated in line with the method used by Weintraub and Hake (1962).

By calculating both individual $\mathrm{d}^{\prime}$ and $\beta$ measures for each pattern type, and group $d^{\prime}$ and $\beta$ measures for each signal and noise intensity, it was possible to both analyze for signiticant differences between discriminations of pattern types over Ss, as well as investigate the various relationships between pattern types and changes in signal and noise intensities.

Considering the psychophysiological importance of these $L$ and $\Theta$ parameters, as well as the experimental paradign described above, the detection task was that of detecting "signals specified exactly [Green \& Swets, 1966, p. 162]." In this case, it has been shown that, for the ideal detection:

$$
\mathrm{d}^{\prime}=\left(2 \mathrm{ES}_{\mathrm{S}} \mid \mathrm{N}_{\mathrm{o}}\right)^{1 / 2},
$$

where $\mathrm{E}_{\mathrm{S}}=$ signal intensity $\left(\sigma_{\mathrm{XS}}\right)$ and $\mathrm{N}_{\mathrm{O}}=$ noise intensity $\left(\sigma_{\mathrm{XN}}\right)$.

Using log transforms of both sides of Eq. 1, this becomes in general:

$$
\log \left(\mathrm{d}^{\prime}+\mathrm{k}\right)=a\left[\log \left(\sigma_{\mathrm{XS}}\right)-\log \left(\sigma_{\mathrm{XN}}\right)\right]+\beta .
$$

That is, the $\log$ of the detectability function $\left(d^{\prime}\right)$ is linearly related to the difference in the $\log$ values of the signal and noise intensities.

With this characterization of patterns, it was expected that discrimination performance $\left(d^{\prime}\right)$ would increase with differences in $\sigma_{\mathrm{XS}}$ and $\sigma_{\mathrm{XN}}$ for $\mathrm{L}, \Theta$, and $L \Theta$ patterns in accordance with Eq. 2. Yet no a priori predictions could be related to the case of detecting 
Table 1

Standard Deviations for the Six Levels of Pattern "Intensities"

\begin{tabular}{lccccccc}
\hline Variable & $\mathrm{N}_{1}$ & $\mathrm{~N}_{2}$ & $\mathrm{~N}_{3}$ & $\mathrm{~S}_{\mathbf{1}}$ & $\mathrm{S}_{2}$ & $\mathrm{~S}_{3}$ & Description \\
\hline Orientation $(\theta)$ & 1.41 & 1.27 & 1.16 & 0.97 & 0.89 & 0.82 & $\sigma_{\theta}$ \\
Line Length $(\mathrm{L})$ & 1.41 & 1.27 & 1.16 & 0.97 & 0.89 & 0.82 & $\sigma_{\mathbf{L}}$ \\
Both $\theta, \mathrm{L}(\mathrm{L} \theta)$ & 1.99 & 1.80 & 1.64 & 1.37 & 1.26 & 1.16 & $\sigma_{\mathbf{L} \theta}$ \\
\hline
\end{tabular}

differences between $\mathrm{L}$ and $\Theta$ distributions, since these two parameters have not been compared in this way before.

The integration model (Green \& Swets, 1966, p. 238) contends that the detections of two independent signals, under the Gaussian assumption, combine to form an additive detection function of the form:

$$
\left.\mathrm{d}_{1,2}^{\prime}=\left(\mathrm{d}_{1}^{\prime}{ }^{2}+\mathrm{d}_{2}^{\prime}\right)^{2}\right)^{1 / 2}
$$

Performance results for $L$ and $\Theta$ pattern parameters in the form of Eq. 2 support the Gaussian assumption (Green \& Swets, 1966, p. 58), and L, $\Theta$ are independent variables. It was thus hypothesized that $L$ and $\Theta$ discrimination functions $\left(d_{L}^{\prime}, d_{\Theta}^{\prime}\right)$ would combine according to this model, where, in log form:

$$
\log d_{L \Theta}^{\prime}=a \log \left(d^{\prime}{ }^{2}+d^{\prime}{ }^{2}\right)+b
$$

The properties of $\beta$, response criterion, for the ideal observer, in a pattern discrimination task as defined above, are more simply defined than those of $d^{\prime}$. For ideal detectors, it is expected that decisions are made according to likelihood ratios, as, for example, occurs with the Neyman-Pearson objective (Green \& Sets, 1966 , p. 21-23). That is, $\beta$ would remain constant while $d^{\prime}$ varies.

\section{METHOD}

\section{Subjects}

The Ss were 40 undergraduate students at the University of Neucastle, who volunteered for the experiment. All reported no known visual detects. They were allocated into two groups of $20 \mathrm{Ss}$.

\section{Stimuli and Apparatus}

Six different Gaussian patterns, consisting of 16 lines each, were generated for $L, \Theta$, and $L \Theta$ pattern types (Fig. 1), giving a total of 18 patterns. Each pattern was characterized by its standard deviation $\left(\alpha_{\mathrm{L}}, \sigma_{\Theta}, \sigma_{\mathrm{L} \Theta}\right)$ as all were equated on means (Table 1 ).

These intensity levels, for each pattern type, were divided into three noise levels $\left(N_{1}, N_{2}, N_{3}\right)$ and three signal levels $\left(S_{1}, S_{2}, S_{3}\right)$ (Table 1). Each noise pattern was duplicated and both identical patterns were photographed on a $35-\mathrm{mm}$ slide. Five duplicates were made from each such noise slide. The signal slides were made from pairing each signal pattern $\left(S_{1}, S_{2}, S_{3}\right)$ with each noise pattern $\left(N_{1}\right.$. $N_{2}, N_{3}$ ) and photographed on a $35-\mathrm{mm}$ slide. This process gave a total of 9 signal slides and 15 noise slides for each $L, \Theta$, and $L \Theta$ pattern type. The slides were left in negative form, with a black background and white figure.

Group I received three presentations of each noise level and Group 11 received the total five duplicates of the three noise levels. Both groups received the wholc nine signal slides for each pattern type. 'The aim of varying the number of noise slides was to endeavor to induce different criteria in $S$ s as well as to check the reliability of $d^{\prime}$ and $\beta$.

The slides were presented to each $S$ by means of a Kodak Carousel (S) slide projector onto the back of a small screen. This screen was tixed at the end of a viewing box, such that each $S$ saw wach slide at a visual angle of $3 \mathrm{deg}$. The exposure time for each slide was controlled by means of a Lafayette tachistoscopic shutter. and was $150 \mathrm{msec}$. A PDP- 12 computer controlled the order of slide presentation, exposure time, and interstimulus interval. Responses ("same" or "different") were recorded manually.

\section{Procedure}

The various slides were allocated randomly, for $\sigma_{X_{N}}$ and $o_{x S}$ differences and pattern type, over presentations. Ss were told they would reccive slides which contained two patterns per slide. These patterns would be either sane or different in form features, and they were to respond by saying either "same" or "different." They werc also told that each slide would be shown briefly, after which they were to respond quickly within a $10-\mathrm{sec}$ interval. Each $S$ was given four pretest trials.

Table 2

\begin{tabular}{|c|c|c|c|c|c|c|}
\hline & \multicolumn{6}{|c|}{ Pattern Type } \\
\hline & \multicolumn{2}{|c|}{$\mathrm{L}$} & \multicolumn{2}{|c|}{$\theta$} & \multicolumn{2}{|c|}{$L \theta$} \\
\hline & Mean & $\mathrm{SD}$ & Mean & SD & Mean & SD \\
\hline \multicolumn{7}{|l|}{ Group I } \\
\hline Percent Correct & 76.60 & 6.90 & 88.60 & 6.90 & 79.40 & 10.96 \\
\hline $\mathrm{d}^{\prime}$ & 0.47 & 0.58 & 2.27 & 0.40 & 1.63 & 0.37 \\
\hline$\beta$ & 1.60 & 0.69 & 1.50 & 0.64 & 1.93 & 1.01 \\
\hline \multicolumn{7}{|l|}{ Group II } \\
\hline Percent Correct & 58.60 & 7.53 & 85.00 & 5.73 & 76.95 & 9.06 \\
\hline $\mathrm{d}^{\prime}$ & 0.54 & 0.44 & 2.14 & 0.42 & 1.63 & 0.57 \\
\hline$\beta$ & 1.39 & 0.47 & 1.05 & 0.29 & 1.33 & 0.53 \\
\hline
\end{tabular}

Means and Standard Deviations of Percentage Correct, $d^{\prime}$, and $\beta$ Values for Each Subject Over the Two Groups 
Table 3

Averaged d' Values Over Signal and Noise Increases for Both Groups

\begin{tabular}{llrrrrrr}
\hline & & $\mathrm{S}_{1}$ & $\mathrm{~S}_{2}$ & $\mathrm{~S}_{3}$ & $\mathrm{~N}_{3}$ & $\mathrm{~N}_{2}$ & $\mathrm{~N}_{1}$ \\
\hline \multirow{3}{*}{ Group I } & $\mathrm{L}$ & -0.03 & 0.33 & 0.86 & -0.06 & -0.15 & 1.38 \\
& $\theta$ & 2.49 & 2.56 & 2.81 & 2.18 & 2.54 & 3.13 \\
& $\mathrm{~L} \theta$ & 1.13 & 1.92 & 2.11 & 0.81 & 1.66 & 2.69 \\
& $\mathrm{~L}$ & 0.18 & 0.63 & 1.20 & 0.39 & 0.55 & 1.07 \\
Group II & $\theta$ & 2.63 & 2.81 & 3.02 & 2.59 & 2.57 & 3.30 \\
& $\mathrm{~L} \theta$ & 1.58 & 1.72 & 2.25 & 1.27 & 1.99 & 2.30 \\
\hline
\end{tabular}

Table 4

Means and Standard Deviations of $d^{\prime}$ and $\beta$ Values for Each Signal and Noise Intensity Over Subjects for the Two Groups

\begin{tabular}{|c|c|c|c|c|c|c|}
\hline & \multicolumn{6}{|c|}{ Pattern Type } \\
\hline & \multicolumn{2}{|c|}{$\mathbf{L}$} & \multicolumn{2}{|c|}{$\theta$} & \multicolumn{2}{|c|}{$\mathbf{L} \theta$} \\
\hline & Mean & SD & Mean & SD & Mean & $\mathrm{SD}$ \\
\hline Group I $\begin{array}{l}\mathrm{d}^{\prime} \\
\beta\end{array}$ & $\begin{array}{l}0.39 \\
1.31 *\end{array}$ & $\begin{array}{l}0.85 \\
0.61\end{array}$ & $\begin{array}{l}2.62 \\
0.92 *\end{array}$ & $\begin{array}{l}0.52 \\
0.45\end{array}$ & $\begin{array}{l}1.72 \\
1.19^{*}\end{array}$ & $\begin{array}{l}0.97 \\
0.71\end{array}$ \\
\hline Group II ${ }_{\beta}^{\mathrm{d}^{\prime}}$ & $\begin{array}{l}0.67 \\
1.23^{*}\end{array}$ & $\begin{array}{l}0.55 \\
0.29\end{array}$ & $\begin{array}{l}2.82 \\
0.94^{*}\end{array}$ & $\begin{array}{l}0.43 \\
0.50\end{array}$ & $\begin{array}{l}1.85 \\
0.96^{*}\end{array}$ & $\begin{array}{l}0.63 \\
0.60\end{array}$ \\
\hline
\end{tabular}

${ }^{*} p>.05$

\section{RESULTS}

Percentage correct scores were calculated for each $\mathrm{S}$ over the various pattern types for both groups. Means and standard deviations for the groups are shown in Table 2 .

Hit and false-alarm probabilities were calculated in two ways. In order to obtain individual $\mathrm{d}^{\prime}$ and $\beta$ values per $S$, hit and false-alarm probabilities were calculated for each pattern type, over signal and noise intensity differences. Means and standard deviations are shown in Table 2. A two-way repeated measures analysis of variance was computed on individual Ss' $d^{\prime}$ over pattern types for each group. Using Keppel's (1973) notation, this was a Gp $\times$ (LO x Ss) design $[2 \times(3 \times 20)]$.

The results indicated an insignificant group difference, but a significant pattern type (LO) difference $[F(2,57)=181.75, p<.01]$. . Scheffé post hoc analyses (Winer, 1962) were computed between $L, \Theta$, and $L \Theta$ levels of the $L \Theta$ factor. Results indicated that $\mathrm{L}$ differed significantly from the $\mathrm{L} \Theta$ and $\Theta$ data $(\mathrm{p}<.05)$.

Hit and false-alarm probabilities were then calculated over Ss for each signal and noise intensity combination and pattern type. From these values, $d^{\prime}$ and $\beta$ scores were tabulated, and averaged scores are shown in Tables 3 and 4 . An analysis of variance was not computed on this data as it would have been a single-entry-per-cell design with repeated measures (Winer, 1962, p. 354) requiring quasi $F$ ratios, and would not have contributed extra information to what had been gained from the above analysis. These group $\mathrm{d}^{\prime}$ scores, and signal and noise intensities, were transformed to $\log$ values in $\log _{\mathrm{e}}\left(\mathrm{d}^{\prime}+1\right)$ and $\log _{\mathrm{e}}\left(\sigma_{\mathrm{X}}\right)$ forms. The $\log _{\mathrm{e}}\left(\mathrm{d}^{\prime}+1\right)$ scores were then correlated with differences in log signal and noise intensities for each pattern type, over the various signal and noise values (Table 5), for each group.

Standard errors of the correlation coefficients $\left(o_{\mathrm{yx}}\right)$ and coefficients of determination were calculated (Table 5; Hays, 1963). Considering the proportional reduction of variance on the dependent variable, given the linear regression rule $\left(\mathrm{r}^{2}\right.$; Hays, 1963, p. 502), and the significant correlations, these results indicated support for a linear regression between $\log _{e}\left(d^{\prime}+1\right)$ and differences between logs of signal and noise intensities.

$\log d^{\prime}$ values for $L$ and $\Theta$ were then formed as $1 / 2 \log _{e}\left(d^{\prime 2} L+d^{\prime 2} \Theta\right)$ and correlated with $\log d^{\prime} L \Theta$ values over signal and noise intensities, for each group. For Group I, $r=0.67(p<.025)$, and for Group II, $r=0.65(\mathrm{p}<.05)$.

It has been shown by Blair, O'Connor, and Pollatsek (1970, p. 118) that the log of the likelihood ratio is normally distributed. Since $\beta$ is a specific variate of this ratio, $\log \beta$ values were calculated for each observed $\beta$, over the various signal and noise intensities and pattern types, for both groups. By means of this $\log$ transformation of $\beta$ differences between $\beta$ values could be tested by Student t tests. Results indicated that none of the observed $\beta$ values differed significantly over increases in signal and noise intensities (Table 4).

\section{DISCUSSION}

The analysis of variance indicated that in terms of detectability $\left(d^{\prime}\right)$ of differences, the L-type patterns were more difficult to discriminate than the $L \Theta$ - and $\Theta$-type shapes. This conclusion is also supported in terms of the percentage correct scores (Table 2) over Ss for both groups.

This ordering of pattern type difficulty was preserved when $d^{\prime}$ and $\beta$ values were calculated over Ss, and not over various presentations of pattern types (Table 4). It may well be argued that this difference was purely a property of the sensitivity to the various parameters, since $\beta$ was not found to differ although

Table 5

Correlations Between $\log _{e}\left(\sigma_{x_{N}}\right)-\log _{e}\left(\sigma_{x_{S}}\right)$ and $\log _{e}\left(d^{\prime} x_{x}+1\right)$ $[\mathbf{x}=\mathbf{L}, \theta, \mathbf{L} \theta$ Pattern Types] Over Groups, Standard Errors of Correlations $\left(\sigma_{\mathrm{yx}}\right)$, and Coefficients of Determination $\left(\mathrm{r}^{2}\right)$

\begin{tabular}{lllll}
\hline & & $\mathrm{L}$ & \multicolumn{1}{c}{$\theta$} & $\mathrm{L} \theta$ \\
\hline \multirow{3}{*}{ Group I } & $\mathrm{r}$ & $0.89^{* *}$ & $0.80^{* *}$ & $0.94^{* *}$ \\
& $\sigma_{\mathbf{y x}}$ & 0.05 & 0.07 & 0.04 \\
& $\mathrm{r}^{2}$ & 0.79 & 0.64 & 0.88 \\
Group II & $\mathrm{r}$ & $0.89^{* *}$ & $0.85^{* *}$ & $0.77^{*}$ \\
& $\sigma_{\mathbf{y x}}$ & 0.03 & 0.06 & 0.07 \\
& $\mathrm{r}^{2}$ & 0.79 & 0.72 & 0.60 \\
\hline
\end{tabular}

${ }^{*} p<.05 \quad * * p<.01$ 
$d^{\prime}$ increased over signal and noise intensity differences (Table 4).

The insignificant group differences on both $\mathrm{d}^{\prime}$ and $\beta$ measures indicate that the percentages of signal and noise intensities did not affect performance and criteria adopted by Ss for detecting differences. This result may well be expected if the parameters used are ideal characterizations of the stimuli (and related to the physiology of the receiver), since detection of differences on such stimuli would be virtually "induced" on the Ss, and consequently the effect of changes in stimulus situation would be minimal. However, different techniques of inducing different criteria would have to be considered before this conclusion could be affirmed in any absolute sense.

The significant correlations between $\log _{\mathrm{e}}\left(\mathrm{d}^{\prime}+1\right)$ and signal and noise deviation differences (Table 5) have not been recorded in past research (Zusne, 1970, Chap. 5). This contrast is indicative of the necessity for isolating the two problems of pattern representation and characterization mentioned previously. By the choice of Gaussian distributions, this second problem has been successfully avoided.

A formal language, or mathematical model, for the representation of visual patterns should contain facilities and support for how the various parameters combine. The significant correlations, for both groups, between log transforms of $d_{L \Theta}$ and $\left(d^{\prime 2} L+d^{\prime 2}\right)^{1 / 2}$, indicate support for the integration model, or an additive concatenation of these parameters.

It would seem, then, that a major reason why orientation and line length parameters have not been successful in predicting discrimination performance with random polygons (Zusne, 1970, p. 208), may lie in the basically uncontrolled number of parameters used in such shapes. Indeed, it would seem that, by using the isolation technique described in this experiment, knowledge concerning the discriminability of such parameters can be improved, and basic interactions between them can be predicted and observed.

\section{REFERENCES}

Blair, 'W. C.. Jr., O'Connor, M. F., \& Pollatsek, A. W. A workbook for mathematical psychology. Englewood Cliffs. N.J: Prentice-Hall, 1970.

BreitMeyer, B. G. A relationship between the detection of size, rate, orientation and direction in the human visual system. Vision Research, 1973, 13, 41-58.

Caelli, T. M., \& Keats, J. A. An extended use of moments of two distribution functions for predicting performance in a pattern discrimination task. Journal of Experimental Psychology, 1973, 99, 209-214.

Campbell, F, W., \& Kulikowski, J. J. Orientation selectivity of the human visual system. Journal of Physiology. 1966, 187, 437-445.

GILINSKY, A. S., \& COHEN, H. M. Reaction time to change in visual orientation. Perception \& Psychophysics, 1972, 11, 129-134.

Green, D. M., \& Swets, J. A. Signal detection theory and psychophysics. London and New York: Wiley, 1966.

Hays, W. L. Statistics for psychologists. New York: Holt, Rinehart \& Winston, 1963.

HogG, R. V., \& CRAIG, A. T. Introduction to mathematical statistics. New York: Macmillan, 1965.

Hubel, D. M.. \& WIESEL, T. N. Receptive fields, binocular interaction, and functional architecture in the cat's visual cortex. Journal of Physiology, 1962, 160, 106-203.

Hubel, D. M., \& WIESEL, T. N. Receptive fields and functional architecture of monkey striate cortex. Joumal of Physiology, 1968, 195, 215-243.

KePpel, G. Design and analysis: A researcher's handbook. Englewood Cliffs, N.J: Prentice-Hall, 1973.

Leibowitz, H. W., \& Harvey, O. H., JR. Perception. Annual Review of Psychology, 1973, 24, 207-240.

WeINTRAUB, D. J., \& HAKE, H. W. Visual discrimination, an interpretation in terms of detectability theory. Journal of the Optical Society of America, 1962, 52, 1179-1184.

WINER, B. J. Statistical principles in experimental design. New York: McGraw-Hill, 1962.

Woll, S., Eriksen, C. W., \& Hake, H. W. A forced-choice study of edge detectors in the human visual system. Perception \& Psychophysics, 1970, 9, 247-252.

ZusNe, L. Moments of area and of perimeter of visual form as predictors of discrimination performance. Journal of Experimental Psychology, 1965, 69, 213-220.

ZUSNE, L. Visual perception of form. New York: Academic Press, 1970.

(Received for publication February 20, 1974; revision received July 8,1974 .) 